Lexis Vol. XLII (2) 2018: 405-439

\title{
Azurduy por Anzoátegui: subjetividad femenina y espacio público en Huallparrimachi (1894)
}

\author{
Mariana Libertad Suárez \\ Pontificia Universidad Católica del Perú
}

\section{RESUMEN}

Este trabajo parte de las tensiones entre la noción de derecho universal defendida por el liberalismo republicano en el intersiglo XIX-XX y el reclamo de participación en las esferas política, social y cultural por parte de las mujeres latinoamericanas. En estos años, narradoras, poetas y dramaturgas del continente hicieron de las ficciones históricas un territorio de disputa simbólica, un campo desde donde manifestar sus insatisfacciones y exponer sus demandas. Desde este marco, se propone una revisión de la obra Huallparrimachi (1894), de la escritora boliviana Lindaura Anzoátegui, texto donde la figura histórica de Juana Azurduy es apropiada como recurso de autoescritura y empleada para reflexionar en torno al ingreso de la mujer a los espacios de toma de decisiones.

Palabras claves: Lindaura Anzoátegui, autoescritura, subjetividad femenina, ficciones históricas

\section{AbSTRACT}

This research looks at the tensions between the notion of universal law defended by republican liberalism at the turning-point of the 19th to the 20 th century and the demands for participation in the political, social and cultural fields by intellectual women. In those years, female narrators, 
poets and playwrights made of historical fictions a territory of symbolic dispute, a field from which to express their dissatisfaction and expose their claims. From this framework, I will propose a review of Huallparrimachi (1894), by the Bolivian writer Lindaura Anzoátegui, in which the historical figure of Juana Azurduy is appropriate as a resource for self-writing and used to reflect about the entrance of women to the spaces of political decision making.

Keywords: Lindaura Anzoátegui, self-writing, female subjectivity, historical fictions

[E]n materia social la mujer fue tan poco iniciadora que ni siquiera creó la doctrina que más naturalmente bubiera podido venir de ella. Psicograma sin hiel: Las mujeres no inventan teorias; pero apostolizan muy bien las que inventan los hombres: por ejemplo, el Feminismo

(Vaz Ferreira 1945: 42-43).

Aunque esta sentencia fue pronunciada por Carlos Vaz Ferreira en 1914, es decir, veinte años después de que Lindaura Anzoátegui de Campero publicara Huallparrimachi, ya en varias novelas escritas por autoras latinoamericanas en el intersiglo XIX-XX estaba implícita la creencia de que el cerebro femenino se encontraba naturalmente incapacitado para desarrollar el pensamiento abstracto. De ahí que cualquier intento de teorización por parte de una mujer debiera ser cuestionado, minimizado o, directamente, omitido al momento de aproximarse a los fenómenos o comportamientos sociales.

A esto se suma, además, la vieja tensión entre experiencia y teoría que atraviesa el debate feminista casi desde sus orígenes. Nelly Richard lo sintentiza al afirmar que:

Muchos grupos feministas han generalizado el lugar común de que las mujeres deben combatir toda intelectualización por juzgarla siempre cómplice de la alianza falocrática entre el poder de la razón y la razón como poder. La teoría sería - para estos grupos- un discurso de autoridad culpable de repetir la censura mantenida durante siglos por el dominio conceptual del Logos (masculino) 
sobre la cultura del cuerpo y del deseo que asocia naturalmente lo femenino a lo subjetivo y a lo afectivo, al yo personal (1996: 733).

Así pues, al marcaje genérico de la polaridad creación/apostolización, se sumó la desconfianza de algunas mujeres hacia los procesos de teorización más convencionales y, sobre todo, hacia las instituciones encargadas de avalarlos. Fenómeno que se acentuó en el caso de América Latina, pues "Hay un punto de coincidencia en el que el imaginario femenino del cuerpo-naturaleza y de la lengua-madre se refleja en la concepción tradicionalista del ser latinoamericano como pureza originaria, creando visiones cómplices entre el mito de lo "propiamente" femenino y de lo "propiamente" latinoamericano” (Richard 1996: 736). Todo esto llevó a que, desde mediados del siglo XIX, las intelectuales latinoamericanas diseñaran un tipo específico de ficciones donde la anécdota sería el lugar elegido para ventilar, debatir y contravenir las ideas políticas y filosóficas en boga. Produjeron textos narrativos en los que la inscripción de los personajes dentro de alguno de los moldes subjetivos admitidos como válidos por la sociedad se empleaba para que las voces femeninas intervinieran en el debate público. Se trató de escrituras en las que, si bien se reproducía la diferenciación entre el hombre que abstrae y teoriza, frente a la mujer que experimenta y apostoliza, las autoras insertaron una serie de postulados propios con la solidez suficiente para movilizar las doctrinas dominantes en el campo intelectual.

Aunque se podrían mencionar muchos ejemplos en el continente - como la revisión del ideario de los unitarios que lleva a cabo Rosa Guerra en su novela Lucía Miranda (1860); la intervención del pensamiento abolicionista desde el feminismo, presente en "A Escrava” (1887), de Maria Firmina dos Reis; las reflexiones en torno al modelo liberal y a la distribución del trabajo que se ve en Blanca Sol (1889), de Mercedes Cabello de Carbonera; o bien la defensa de la filosofía positivista expuesta en La evolución de Paulina (1893), de Margarita Práxedes Muñoz- las ficciones históricas creadas en este marco constituyen un corpus particularmente fecundo. 
$\mathrm{Al}$ respecto, es importante recordar que cuando las autoras del intersiglo XIX-XX decidieron escribir ficciones de archivo dejaron en evidencia que la presencia de la mujer - en tanto agente social y no solamente en condición de alegoría- en el espacio público se había producido varias décadas antes de que las obras fueran publicadas. Con ello, se demostraba la insuficiencia de cualquier propuesta teórica que intentara comprender la interacción social desde la evaluación exclusiva de las subjetividades masculinas. En otras palabras, cuando estas ficciones de archivo atravesadas por una mirada feminista iluminaron zonas umbrosas del espacio público, pusieron de manifiesto tanto la capacidad analítica de las mujeres intelectuales como ciertas inestabilidades de las doctrinas que décadas más tarde Carlos Vaz Ferreira le atribuiría al genio masculino.

Lucía (1860), de Eduarda Mansilla; El tesoro de los incas (1865), de Juana Manuela Gorriti; José Antonio Galán. Episodios de la guerra de los comuneros (1870), de Soledad Acosta de Samper; "Cora Campillana" (1873), de Carolina Freyre de Jaimes; o La bija del bandido o los subterráneos del Nevado (1887), de María del Refugio Barragán de Toscano constituyen algunas manifestaciones de esta tendencia a dislocar la Historia que se extenderá en todo el continente. Estas y otras publicaciones servirán de marco para que la voz de la escritora boliviana Lindaura Anzoátegui de Campero emerja en sus tres novelas históricas: Huallparrimachi (1894), En el año 1815 (1895) y la obra póstuma Manuel Ascencio Padilla (1909), textos en los que, por medio de la desestabilización del discurso historiográfico y un solapado proceso de teorización feminista, la autora interviene las fronteras impuestas entre el espacio público y el espacio privado.

Aunque los estudios en torno a la narrativa de Lindaura Anzoátegui de Campero publicados en los siglos XIX y XX son más bien escasos, hay una serie de lecturas insertas en manuales o textos panorámicos que dan cuenta de la posición desde donde se pronunciaba la autora. Fernando Unzueta (1997), por ejemplo, asegura que “La 'persona' pública de Anzoátegui se caracteriza por su 
marcado nacionalismo 'oficialista', alimentado por circunstancias individuales, de clase social e históricas (la guerra y la elección de Narciso Campero, su esposo, como presidente 'reconstructor' de Bolivia, 1880-84)” (222). Posteriormente añade que:

En la sede de gobierno, organizó veladas y conciertos patrióticos, dirigió obras de beneficencia, participó en polémicas (serias y humorísticas) en la prensa y llevó la correspondencia privada del presidente, demostrando ampliamente, según Urquidi, su "ardiente patriotismo" (“Anzoátegui” 85-87). Siguiendo esta línea, una especie de hagiografía secular representa la agonía de la escritora como un caso de "ejemplaridad" legendaria: "la última palabra que musitaron sus labios fue: ¡patria!” (Trigo Paz 38). Anzoátegui, mejor conocida en el ambiente cultural por su pseudónimo "El Novel", también ha sido elogiada por el nacionalismo de su obra literaria. Paredes afirma que "convertida en Primera Dama, dio rienda suelta a su patriotismo con trabajos literarios llenos de civismo y amor a la Patria” (Unzueta 1997: 222-223).

Quizás el primer rasgo que salta a la vista al momento de leer esta descripción es que — más allá de ser una primera dama, es decir, una mujer que se define desde su identidad relacional- ${ }^{1}$ Anzoátegui es evaluada como una persona pública con preferencias políticas claras. Ciertamente, en la América Latina del intersiglo, este perfil no implicaba filiación a un determinado modelo de organización económica o social; ${ }^{2}$ no obstante, sí revelaba el deseo avalar un

\footnotetext{
1 Las referencias a Anzoátegui como una muy buena primera dama son tan frecuentes como aquellas que la consideran una buena patriota. Virginia Ayllón y Cecilia Olivares resumen su biografía afirmando: “nació en 1846 en el Valle de Tojo (limítrofe entre Tarija y Potosí). Antes de cumplir 16 años ya había perdido a su único hermano, a su padre y su madre [...] en 1871 se casó con el general Narciso Campero, a quien acompañó a Europa cuando fue nombrado ministro plenipotenciaro en Francia e Inglaterra [...] Cuando en plena guerra contra Chile, Campero fue nombrado presidente (1880), Lindaura Anzoátegui se dedicó a organizar eventos cuyos ingresos se destinaban a los heridos de guerra; visitaba los hospitales, atendía solicitudes de habitantes de todo el país, se ocupaba de la correspondencia de su marido" (2002: 149). En otras palabras, para estas autoras, el patriotismo y la lealtad a su esposo eran rasgos imbricados en la vida de Anzoátegui.

2 En el intesiglo XIX - XX, la noción de patria y la necesidad de definir sus límites permitió la emergencia de una serie de voces femeninas que, al menos desde una mirada inicial, parecían al servicio de los proyectos políticos más fuertes. La tacneña Carolina
} 
espacio de poder alternativo desde donde construir un territorio de arraigo para la mujer distinto al de la alegoría o al de la madre. $\mathrm{Al}$ respecto, también es importante tener en cuenta la máscara masculina y sus implicaciones posibles. La referencia a que "Anzoátegui [fue] mejor conocida en el ambiente cultural por su pseudónimo 'El Novel'” (Unzueta 1997: 222), si bien es un potencial signo de subordinación, también podría entenderse como un gesto de resistencia. En un primer momento, pareciera que la autora oculta su nombre porque reconoce que el espacio de las letras pertenece solo a los varones; sin embargo, la elección de ese pseudónimo también funciona como una estrategia de usurpación, una argucia que le permite a la autora deslindarse del lugar que le era asignado por distintas instancias de poder. Empleando otros términos, en el aparente gesto de subordinación implícito en la renuncia al nombre propio, hay también un desprendimiento a las lecturas sociales y culturales que se habían hecho de ese nombre.

Entonces, desde este lugar ambiguo, eventualmente transgresor o bien extensivo de la maternidad, la mujer intelectual adquiere la facultad de construir figuras heroicas que, por su apego a uno de los modelos nacionales, trascendieron la dicotomía de género. Al movilizar su propia identidad, por medio de la sustitución de su nombre - que, por cierto, para el momento en que se publican las obras pareciera ser la única posesión posible de una mujer-, Anzoátegui delimita un espacio donde la polaridad hombre/mujer va a ser sustituida por la dicotomía patriota/realista. De ahí que consiga construir personajes femeninos con mayores posibilidades de agencia que los tradicionalmente mostrados por el Romanticismo latinoamericano.

Freyre, por ejemplo, desde una posición profundamente conservadora, se dedicó a arengar a favor de la causa peruana durante la Guerra del Pacífico; asimismo, Angélica Palma, en sus obras, apoyó la visión hispanofílica de la historia nacional peruana; al tiempo que Juana Manso, desde una visión burguesa liberal, defendió también los ideales nacionalistas. Es decir, el hecho de que una mujer asumiera públicamente la palabra para defender un proyecto nacional no estaba asociado a sus preferencias ideológicas. 
Cinco años después de que se publicara el artículo de Unzueta, Virginia Ayllón y Cecilia Olivares (2002), al referirse a Lindaura Anzoátegui, presentaron la muerte de Narciso Campero como un punto de quiebre tanto en la escritura como en la figuración pública de la narradora. Tras catalogarla como una suicida pues, junto con Adela Zamudio, María Virginia Estenssoro e Hida Mundy, "de manera premeditada reali[zó] actos que [la] condenarán no necesariamente a la muerte física, sino a ser protagonista privilegiada de conjeturas y maldiciones" (149), las investigadoras señalan que la narradora publicó:

En el año 1815 (1895), Huallparrimachi (1892), Luis (1892), y Manuel Ascencio Padilla (1909), es decir, novelas casi cívicas, casi patriotas; episodios históricos que compuso después de 1896, año de la muerte de Campero. Pero Lindaura publicó también ¡Cuidado con los celos! (1893), La madre (1891), Una mujer nerviosa (1891) y el libro de estampas populares Cómo se vive en mi pueblo (1892), escritos en la época que transcurrió entre su regreso a Europa y la presidencia de su marido. En estas últimas, el motivo cívico no es el predominante y sí más bien el “ser mujer”. Estas novelas de Anzoátegui son detallados prospectos de lo que la sociedad boliviana del siglo XIX estableció como el deber y el ser mujer. Abnegación y sacrificio son dos de los atributos femeninos más desarrollados por la Anzoátegui en tramas en las que las mujeres cumplen a cabalidad sus papeles de cuidadoras, por un lado, y de víctimas por el otro (2002: 150).

Se habla, entonces, de la emergencia del discurso de Anzoátegui como síntoma de diferentes circunstancias históricas, socioeconómicas o culturales; sin embargo, no deja de ser interesante cómo, tras la muerte de su marido, la autora se desplaza dentro del campo intelectual y se dedica a inscribir su propia subjetividad en lo que, según el consenso, se asumía por entonces como el pasado oficial de la nación boliviana. La reformulación de los acontecimientos originarios con la presencia de subjetividades femeninas centrales obliga al reconocimiento de formas alternativas de ser mujer en el pasado, lo que desembocará en un gesto de legitimación de la propia voz. 
Usando términos más sencillos, se podría afirmar que cuando muere Campero, Anzoátegui dejará de ser la esposa del presidente, para transformarse en una representante de la estirpe de Juana Azurduy. ${ }^{3}$ Ahora bien, esta mutación estuvo seguida de una negociación que involucraba algunos elementos claves, por ejemplo, aunque Juana Azurduy ${ }^{4}$ fuera uno de los personajes centrales de En el año 1815 (1895), Huallparrimachi (1894) y Manuel Ascencio Padilla

3 En su artículo "Letras de mujer. Juana Manuela Gorriti y la imaginación nacional andina, siglo XIX”, Luis Miguel Glave (1996) resume la vida de la heroína boliviana afirmando:

Juana Azurduy luchó aliado de su esposo Manuel Ascencio Padilla en la turbulenta época de los movimientos patriotas contra el dominio español en el Alto Perú. Los patriotas del sur no podían acabar con la hegemonía española en la sierra y ante ella, rebeldes de distintos pueblos llevaron adelante luchas heroicas, desiguales y tenaces. Juana participó en todas las campañas — su terreno de combate era conocido como el de "los guerrilleros Padilla” y, en 1816, muerto su esposo, llevó adelante ella sola los combates, hasta que tuvo que abandonar el territorio altoperuano para refugiarse en la frontera salteña, donde Güemes había puesto en jaque a los realistas. Allí recibió el título de "Teniente Coronela de la Independencia” y fue reconocida -en elevación lírica de la mujer que trota como "ilustre amazona" de la patria. El padre de Juana Manuela [Gorriti] mandaba en Salta -muerto Güemes en último aleteo de los realistas cuando la niña la vio. Luego de la independencia definitiva en 1824, regresó la Azurduy a su tierra, Chuquisaca; lejos de ser premiada, vivió en la pobreza, el ostracismo y la soledad con que las nacientes repúblicas premiaron a las mujeres que lucharon por crear un orden nuevo. Y así la tuvo en su recuerdo Juana Manuela cuando escribiera, sutilmente: "algunos caudillos tuvieron envidia de esa gloria femenina” (94).

4 Elegir como centro del discurso a este y no otro personaje histórico constituye una decisión con implicaciones políticas importantes. Como afirma Vanesa Miseres:

El hecho de que Juana Azurduy se convierta en una mujer guerrera, desempeñando funciones poco usuales para su género en el siglo XIX (aunque esto sí era más común dentro de la tradición indígena), despertó diversas opiniones en su tiempo que destacaron, a favor y en contra, cierto carácter "antinatural” en su proceder [...] Así, por ejemplo, el militar Antonio Beruti le escribe a Belgrano haciendo referencia al "varonil esfuerzo y bizarría de la Amazona doña Juana Azurduy”. Asimismo, al regresar a Chuquisaca, en 1825, la municipalidad la presenta como genio destacado tras haber "olvidado la delicadeza de su género" y la señala como "la única” mujer que participó con heroísmo en el combate, expresión que además ignora la participación del resto de las mujeres. Y, pese al "reconocimiento oficial y honorífico" que el propio Manuel Belgrano había brindado a la labor de Juana Azurduy nombrándola teniente coronel de las milicias, Mitre excluye la figura de Juana como protagonista en su relato de la revolución altoperuana (2014: 400-401). 
(1909), la primera de las obras se titula con una fecha fundacional y las otras dos con el nombre de los protagonistas masculinos; en segundo término, la heroína es, al igual que la autora, la viuda de un fundador nacional, con lo cual, puede atribuirle su amor a la patria y su interés por la organización nacional al papel de esposa que ocupó por años; finalmente, en algún momento de la tres obras, se introduce una pequeña reflexión sobre la noción de verdad que exculpa a la novelista de cualquier intrusión en el espacio reflexivo que debía corresponderles a los hombres. En otras palabras, "saber" y "decir" entran en juego hasta construir un territorio menos arriesgado para la elaboración intelectual. ${ }^{5}$

La efectividad de estas maniobras simbólicas se evidenció en los distintos momentos de recepción de sus novelas. Por ejemplo, en los textos críticos en los que se ha hablado de Huallparrimachi desde el momento de su publicación hasta el siglo XXI, se acepta la posición autoral asumida por Anzoátegui como correcta y hasta loable, aunque los juicios de valor en torno a su obra no sean del todo uniformes. Así es como Fernando Diez de Medina, en Literatura boliviana (1954), incluye el nombre de Lindaura Anzoátegui en el apartado titulado "La guerra del Pacífico y sus alrededores".

Entonces, se podría afirmar que al reivindicar a un personaje con valoraciones tan contradictorias dentro de la memoria oficial, Anzoátegui bien podría haberse expuesto a ser evaluada en términos similares a los que se usaron para juzgar la conducta de su personaje.

5 Dice Josefina Ludmer (1984) en su artículo "Las tretas del débil”, al hablar de las estrategias empleadas por Sor Juana Inés de la Cruz para pronunciarse:

Como si una madre o ama de casa dijera: acepto mi lugar pero hago política o ciencia en tanto madre o ama de casa. Siempre es posible tomar un espacio desde donde se puede practicar lo vedado en otros; siempre es posible anexar otros campos e instaurar otras territorialidades. Y esa práctica de traslado y transformación reorganiza la estructura dada, social y cultural: la combinación de acatamiento y enfrentamiento podían establecer otra razón, otra cientificidad y otro sujeto del saber. Ante la pregunta de por qué no ha habido mujeres filósofas puede responderse entonces que no han hecho filosofía desde el espacio delimitado por la filosofía clásica sino desde otras zonas, y si se lee o se escucha su discurso como discurso filosófico, puede operarse una transformación de la reflexión. Lo mismo ocurre con la práctica científica y política (53).

Con esta base, se podría afirmar que la teorización feminista de Anzoátegui tiene más que ver con una posición de lectura que con la escritura. 
Antes de abordar su escritura, señala que, junto con Adela Zamudio y Julio César Valdés, Anzoátegui es una costumbrista que proclama "gallardamente la urgencia de explotar el tema nacional, perfilando tipos y modos de vida propios” (Diez de Medina 1954: 238), luego añade:

Lindaura Anzoátegui de Campero inicia el costumbrismo propiamente dicho. Sus novelas cortas y cuentos, lo mismo que sus relatos históricos, denotan perspicacia en la sátira social, fino dibujo psicológico, sentimiento estético del paisaje. ¿No ha dicho Jounbert que la literatura es delicadeza? Pues bien: la señora Campero es un alma delicada, cuyas obras, sentidas y armoniosamente logradas, contrastan con el barroquismo [sic] ambiente. Es «la mejor prosa escrita en Bolivia por pluma femenina», afirma un crítico. Por la habilidad con que plantea y resuelve los conflictos pasionales, se advierte un temperamento dramático que no llegó a florecer en plenitud. Huallparrimachi, Una mujer nerviosa, Luis, y otras narraciones, denotan un temperamento realista y romántico al mismo tiempo, bien controlado, que sortea diestramente las vallas del relato (Diez de Medina 1954: 239).

Asimismo, indica: “Otro ensayista apunta: 'Maneja muy bien el diálogo, y es de tal valor plástico, que informa por sí solo de toda la acción y trasluce el escenario o fondo'. Doña Lindaura vio y expresó las escenas habituales de su Bolivia, como Fernán Caballero transcribió las de su España [...] fue también una rara poetisa de rara distinción espiritual” (Diez de Medina 1954: 239-240).

El primer fragmento citado evidencia que algunas de las tretas desplegadas por Anzoátegui para ingresar al campo cultural dieron un resultado favorable. Diez de Medina, contrariamente a lo que solía ocurrir con la crítica dirigida a la escritura de mujeres a mediados del siglo XX, no presenta ni la obra de esta autora ni la de Adela Zamudio como discursos deshistorizados, al contrario, inscribe Huallparrimachi y otras narraciones de Anzoátegui dentro del Costumbrismo, al tiempo que le otorga a la autora la categoría de fundadora y la presenta como una subjetividad intelectual apta 
para instituir dentro de una sociedad determinada, la ética y la estética de un movimiento literario.

Pese a tomar ese riesgo o quizás como una fórmula de compensación, una vez que se ha reconocido que Anzoátegui tiene la capacidad analítica suficiente para formular una crítica social, Diez de Medina se dedica a destacar aquellos atributos de la autora que podían entenderse como estereotípicamente femeninos. Entonces, se habla de "armonía", "sentimiento" y "delicadeza” para, posteriormente, reconocer que su escritura es notable solo si se le contrapone a la de otras mujeres. No deja de ser interesante, al respecto, la comparación de El Novel con Fernán Caballero, otra autora que se valió del pseudónimo masculino para poner en circulación sus obras, pues el paralelismo señala que aunque quizás no sea posible del todo registrar a Anzoátegui dentro de la historia oficial de la literatura boliviana, sí existe la opción de construir movimientos o genealogías de mujeres intelectuales de habla hispana.

Es importante considerar al respecto que para el momento en que publican sus obras, tanto Fernán Caballero (Cecilia Böhl de Faber y Larrea, española, nacida en Suiza en 1796 y fallecida en España en 1877) como Lindaura Anzoátegui (nacida en 1846, en el Valle del Tojo), todavía no les habían sido reconocidos los derechos civiles y políticos a las mujeres. Jurídicamente, ambas autoras funcionaban como menores de edad, quizás por ello, Diez de Medina enfrenta la necesidad de atribuir la competencia analítica de ambas narradoras a su "capacidad de ver" (1954: 239) pues, dentro de su idiosincrasia, podía resultar altamente disonante que una mujer tuviera la madurez y la formación necesarias para analizar y, posteriormente, esbozar alguna reflexión teórica.

Había pues un reconocimiento del discurso, de la subjetividad de la autora, de su mirada crítica, pero dentro de una sociedad regida bajo la lógica binaria que rechazaba la participación pública de la mujer, de ahí que la evaluación presentara tantas tensiones. De hecho, tan solo un año después de que se publicara el libro de Diez de Medina, Enrique Finot (1955), en su Historia de la literatura boliviana, afirmaba: 
La crítica boliviana ha sido no solamente benévola sino encomiástica para la señora Anzoátegui de Campero, esposa del presidente de la república D. Narciso Campero. No hay duda que la [sic] escritora merecía los elogios que le fueron prodigados, independientemente de su situación social y de familia.

La señora Campero murió al poco tiempo de haber dado a la estampa sus primeros ensayos novelescos. De no haber sido así, seguramente habría dotado a las letras bolivianas de otras obras maduras y dignas de justa fama (198).

Luego de recordar que Anzoátegui no llegó a alcanzar del todo su adultez, indica:

Lo interesante en esta novela es el carácter nativista del tema y de los personajes, que señalan a la autora como francamente afiliada entre los escritores que se inspira en el ambiente nacional. No hay exageración en afirmar que Juan de la Rosa de Nataniel Aguirre y Huallparrimachi son las dos únicas novelas realmente bolivianas escritas en Bolivia y por autores bolivianos durante el siglo XIX (Finot 1955: 198).

Aunque la paradoja enfrentada por Fernando Diez se enfatiza en este caso, el texto de Finot asoma algunas otras tensiones útiles para pensar la figura de Anzoátegui en el campo cultural. Por ejemplo, resulta altamente llamativo que, dentro de un libro dedicado a sistematizar la literatura boliviana, la autora sea presentada primero como una "señora"; luego, como la primera dama; posteriormente, como una mujer bien tratada por la crítica y, solo después que todo ello ha sido dicho, se señale que los elementos enumerados no tienen conexión entre sí. Es decir, aunque se trate de un libro de literatura, el estado civil de la autora parece un dato más importante que su narrativa para el crítico Finot.

Esta jerarquización de los rasgos definidores de Anzoátegui contrasta abiertamente con la referencia a la bolivianidad de su obra. Según lo expuesto por Finot, esta escritora consiguió comprender y construir la personalidad nacional, enunciarla desde el territorio boliviano y así “iniciar” ya no solo el Costumbrismo, como 
indicaba Diez de Medina, sino la literatura de su país en general. Es decir, aunque en principio, se lee la voz de Anzoátegui desde las ordenaciones genéricas que ubican a la mujer como un ente complementario que eventualmente podría tomar la palabra siempre que lo hiciera desde el interior del hogar o desde la obediencia implícita en el matrimonio; de inmediato se señala que ella tuvo la potestad de intervenir tanto el espacio público como la historiografía literaria.

En resumen, aun varias décadas después de su publicación, la escritura de Lindaura Anzoátegui de Campero fue visible para algunas instituciones canonizantes de la literatura boliviana como la crítica literaria o los manuales escolares y, si bien en muchos casos los investigadores reemplazaron el texto por la biografía y/o la corporalidad de la autora y, en otros tantos, la presentaron como una narradora en proceso de formación, también es cierto que, en los discursos que incorporaban Huallparrimachi a la historia de la literatura, se pueden rastrear una serie de elementos emergentes que hablaban de un perfil más o menos potente y definido de la mujer intelectual.

Así pues, Anzoátegui, para el momento de la publicación de sus novelas históricas, gozaba de la autoridad suficiente para dislocar los roles de género o, lo que es lo mismo, las reflexiones de la escritora acerca de la feminidad contenida en sus primeros textos le permitieron convertir su identidad en un lugar de poder desde donde diseñó un modelo de patria. Esto va a ser registrado con más detenimiento en las aproximaciones a su obra publicadas en el siglo XXI. Por ejemplo, en el año 2006, casi una década después de la aparición de "Género y sujetos nacionales: en torno a las novelas históricas de Lindaura Anzoátegui” (1997), Unzueta publicó el artículo "Las republiquetas y los límites de la historiografía" (2006). El investigador destaca que cuando Anzoátegui escribe Huallparrimachi ubica a las tropas guerrilleras por encima de aquellas que estaban comandadas por porteños (Unzueta 2006: 130), del mismo modo, apunta que:

Al mitificar la figura de Huallparrimachi y considerarlo como posible descendiente de los Incas, «sagrado y querido» por su gente, la novela revitaliza la tradición indianista en un contexto 
abiertamente nacionalista. Destaca, además, el «numeroso auxilio de los indios» a los ejércitos auxiliares y, a pesar de la idealización del protagonista y la representación de los demás indígenas como víctimas, establece una alianza simbólica entre estos y el proyecto nacional criollo. La obra también traza un paralelo entre Leoncio, un indio, y Pérez Cueto, un exseminarista de Chuquisaca; ambos se arrepienten de haber apoyado a los realistas y vuelven a su lugar «natural» en la lucha por la patria, al lado de los guerrilleros. En la imaginación histórica de Huallparrimachi, entonces, el movimiento popular de las republiquetas, dirigido por sectores criollo-mestizos de provincia, establece alianzas simbólicas con otros grupos sociales del país: las mayorías indígenas, y los doctores citadinos (131).

Unzueta estaría reconociendo en la escritura de Anzoátegui al menos dos finalidades claras: nacionalizar el linaje Inca y desligarse del proyecto liberal de nación. ${ }^{6}$ Esta propuesta no era del todo novedosa pues, como bien explica Cecilia Méndez (1995), ya en siglo XVIII, no solo en Bolivia sino también en Perú, se había instaurado una "retórica de exaltación del pasado imperial por parte de los criollos [que] se hizo aún más evidente en la época de

6 Esta apreciación no solo fue expuesta por Unzueta. Virgina Ayllón, una década después de haber publicado el artículo "Las suicidas: Lindaura Anzoátegui, Adela Zamudio, María Virginia Estensoro e Hilda Mundy” (2012) indicaba que:

Lindaura [desarrolló una literatura] asentada en el centro del siglo XIX. Sus noveletas —escritas entre 1891 y 1895 - tienen el objetivo de dibujar la naciente sociedad boliviana en general y de la mujer boliviana en particular. En este intento indaga en tres elementos para ella centrales en la construcción del ser mujer de ese siglo: la mujer, la iglesia y la impronta indígena [...] Cuidado con los celos (1893) es una novela muy bien estructurada que expone, en paralelo, la demanda social de sacrificio de mujeres e indígenas: el sacrificio de la madre y el sacrificio del indio como dos caras de la misma moneda en la sociedad boliviana del siglo XIX [...] Es llamativo que ciertos críticos hayan calificado a la obra de Anzoátegui (especialmente su novela Huallparrimachi) como evidentemente nacional y que junto a Juan de la Rosa de Nataniel Aguirre serían las únicas novelas del XIX que habrían tratado lo evidentemente nacional en sus novelas. Pero más interesante es que su novelística elabora algunos rasgos de lo que después (con Clorinda Matto de Turner) sería el indigenismo a través de la sublimación de lo indígena, de la calificación positiva de sus rasgos constitutivos en contraposición de lo criollo (Ayllón 2012: 410).

Es decir, también en este texto se reafirma que la reconstitución del pasado que lleva a cabo Anzoátegui implica un replanteamiento étnico y genérico del sujeto nacional. 
la independencia” (31). Con este recurso, se conseguía neutralizar "el sentido político que pudieran tener las expresiones propias de los indios” y aceptar su presencia solo como parte del paisaje o como gloria lejana (Méndez 1995: 32). En el caso particular de Anzoátegui, todo parece indicar que, con esta visión del indígena, se pretendía replantear el modelo de feminidad republicano. Si la nación no había sido construida ni fundada por la burguesía liberal sino por los movimientos guerrilleros, si los comandantes porteños estaban llenos de vanidad y entorpecían los planes llevados a cabo en el escenario de guerra y, sobre todo, si se perpetuaba la idea del indígena como un ser frágil que requería afecto y guía maternal, entonces, nada justificaba que la mujer hubiera permanecido recluida en el espacio privado ni durante la fundación de la nación ni en la Postguerra del Pacífico.

Esto se hace evidente desde las primeras páginas de la obra; ${ }^{7}$ no obstante, a veces se vela con los juegos con la dicotomía ficción/ realidad. Por ejemplo, en un movimiento contrario a la tradición de escritura del romanticismo latinoamericano, cuando la voz narrativa menciona por primera vez al protagonista masculino, en una nota al pie de página, se precisa:

El Sr. Octavio Moscoso en sus estimables Apuntes Biográficos de los Protomártires de la guerra de la Independencia del Alto Perú (boy Bolivia). Dice: que "Juan, conocido con el nombre de Huallparrimachi, que eligió por cariño en memoria de uno de sus antepasados, pertenecía por su madrea la estirpe de los Incas, y a la de los reyes de España por su padre. El célebre caudillo Don Manuel Asencio Padilla, tomó a su cargo la suerte de Juan, cuyos dotes físicos y morales, le granjeaban la simpatía general. Poseía un talento sobresaliente y un corazón tan tiernamente apasionado, que todas sus poesías, escritas en el idioma de sus abuelos, respiran una dulce melancolía y en veces un dolor tan intenso, que desgarran el alma”.

Todas las citas textuales fueron tomadas de la reedición más reciente de la obra, incluida en el volumen Desafío de mujer: vivir sin el velo de la ilusión: obras de Lindaura Anzoátegui Campero de Campero, publicado en La Paz, durante el año 2006 por la editorial Plural. 
Sentimos no conocer las poesías aludidas. Según el autor a que nos referimos, Huallparrimachi murió en el hecho de armas del 2 de agosto de 1816; nosotros nos permitimos hacerlo figurar algunos meses después, contando con que nuestros lectores nos perdonen este inofensivo anacronismo (Anzoátegui de Campero 2006: 163).

Esta declaración obliga a recordar las reflexiones en torno a la tríada verdad-ficción-historia que presentaban algunos autores del romanticismo como uno de los ejes fundamentales de la escritura. Por ejemplo, en la carta que Juan Zorrilla de San Martín le dirige a su esposa y que funciona como texto introductorio del poema Tabaré, publicado en 1888, se indica: "El poeta no puede decir mentiras, por más dulces que ellas sean. ¿Te ríes? Pues, no te lo digo en broma. El arte es verdad, la alta verdad inoculada en la ficción, como un soplo vivificante y eterno; de ahí que la verdad, lo real en el arte, no esté en la forma, como lo eterno del hombre no está en el cuerpo" (Zorrilla de San Martín 1955: 5); asimismo, en el prólogo de Julia: o, escenas de la vida en Lima, Luis Benjamín Cisneros indica que, entre otras motivaciones, escribió su libro:

Por manifestar que la vida actual de nuestra sociedad no carece absolutamente de poesía, como lo pretenden algunos espíritus. El ridículo frívolo y la crítica hiriente se han apoderado muchas veces de nuestras costumbres; pero nadie ha estudiado hasta ahora su bella, elevada y poética. Hay sin embargo en nuestra existencia social, en nuestra vida íntima de familia y en nuestros hábitos populares, un horizonte abierto a la poesía, a la contemplación y al romanticismo (Cisneros 1861: vii-viii).

De igual manera, en la “Explicación” que precede Amalia, de José Mármol, el autor señala:

La mayor parte de los personajes históricos de esta novela existen aún, y ocupan la misma posición política o social que en la época en que ocurrieron los sucesos que van a leerse. Pero el autor, por una ficción calculada, supone que escribe su obra con algunas generaciones de por medio entre él y aquéllos. El autor ha creído que tal sistema convenía tanto a la mayor claridad de la narración cuanto al porvenir de la obra (Mármol 1987: 1). 
Por su parte, Sylvia Molloy propone que, según el propio Sarmiento, Facundo integra "una cadena documental, una configuración de letras previas y letras futuras que le dan legitimidad. Toma su autoridad del documento que lo precede y se vuelve así documento capaz de autorizar a su vez textos posteriores" (Molloy 1988: 409). A esto, Enrique Bruce Marticorena (2013) agrega que "Muchos escritos en la historia literaria de Occidente se resuelven 'poéticos', en mucho por una impostura, por una imprevista superposición genérica", por eso no es extraño que "en el caso de Facundo, la pretendida prosopopeya, subgénero de la historiografía caro a las prescriptivas del XIX, se afirm[e] en su sitial poético e iluminador ya desde la Advertencia al lector del propio Sarmiento" (188).

A diferencia de estas voces canónicas, Anzoátegui no defiende su capacidad de designar la realidad mediante la escritura de poética o narrativa ni tampoco se propone hallar algo dentro de las verdades existentes. Por el contrario, la nota al pie aclara que, aunque parezca que la obra manifiesta verdades incómodas, como la presencia de una mujer en la construcción nacional o los orígenes indígenas del sujeto nacional, su discurso está tan inmerso en la ficción que parte de un anacronismo irónicamente calificado de "inofensivo". No es arriesgado afirmar entonces que la confesión de esta deficiencia en su novela es otra de las muchas estrategias empleadas por la autora para negociar su ingreso al campo intelectual sin resultar amenazante. Treta que, además, entra en tensión con sus referencias permanentes a las fuentes bibliográficas consultadas. Usando la terminología de Scott (1990: 27), podría decirse que al contrariar la tradición que hacía de narradores y poetas portadores de verdades, la autora está haciendo público su deseo de intervenir la historiografía boliviana oficial o, lo que es lo mismo, poniendo al descubierto lo que había sido por años el sentido oculto de su escritura.

Por añadidura, en este mismo fragmento, Anzoátegui confiesa no haber leído la obra poética escrita por su personaje. Es decir, ella —en su condición de mujer letrada— no se aproximó a la figura de Huallparrimachi por su poesía, sino que lo analizó como personaje histórico, lo que equivale a decir que lo convirtió en su objeto 
de estudio. Indudablemente, se trata de una transgresión del lugar de la mujer intelectual que, si bien estaba facultada para "apostolizar" las propuestas de los grandes ideólogos, no debía mostrarse como conocedora del espacio público, portadora de un saber analítico ni, en modo alguno, como una voz más racional que emocional. $\mathrm{Al}$ reconstruir el espacio social, Anzoátegui estaría abandonando el lugar de la testigo que habla con base en su experiencia al interior del hogar y, al mismo tiempo, estaría asumiendo el control ideológico del discurso y de los acontecimientos.

Entonces, la subjetivación de la mujer letrada se va a ver alterada durante la escritura de esta obra y, como consecuencia de ello, el proceso de (autor)ización de Anzoátegui se dará en términos distintos a los que solían determinar a las figuras femeninas en la posguerra del Pacífico. La narradora participará en la construcción nacional no como madre, sino como investigadora de los hechos, por ello, logra desplazar muchos significantes históricos, entre los que destaca la corporalidad del hombre indígena. En esta misma nota al pie, se recuerda que Octavio Moscoso había subrayado la simpatía que despertaba Juan Huallparrimachi en una figura tan cercana al sujeto nacional idealizado en la Bolivia del intersiglo como Manuel Ascencio Padilla; no obstante, también se aclara que esta afinidad no estaba vinculada al potencial guerrero, sino a los "dotes físicos y morales" y el "talento sobresaliente y el corazón tan tiernamente apasionado" (2006: 163) del representante de los incas. Con ello, Anzoátegui propone una reflexión en torno a las fronteras que separaban clases, géneros y etnias en la constitución del espacio público.

Es curioso que no sea la voz narrativa sino la voz autoral que enuncia las notas aclaratorias la que describe al hombre indígena como virtuoso y bello - tal y como le hubiera correspondido a cualquier heroína romántica一; al hombre mestizo occidentalizado como maternal pues prohíja al poeta e intenta protegerlo; y al historiador, el otro varón letrado, como el encargado de certificar esta relación amorosa. Si se piensa este hecho considerando el lugar que ocupan los tres agentes dentro del imaginario boliviano, resultaría imposible pensar que Anzoátegui va a reproducir la dicotomía amor 
romántico/razón propia de la novela decimonónica. Polaridad que, en muchos casos, también sustentaban otros pares mínimos como contemplación/acción o espacio privado/espacio público.

Adicionalmente, el hecho de que el historiador, el héroe y el indígena ganado a la causa independentista se impregnen de emociones comprendidas hasta ese momento como femeninas movilizará algunas otras identidades antes opacadas, como la de la mujer guerrera. Ello explica por qué, por ejemplo, la reubicación de las figuras masculinas dentro del mapa nacional se narra en un apartado que lleva por título "Juana Azurduy de Padilla”:

La brisa, tibia como una caricia, mece suavemente el espeso follaje del corpulento ceibo, bajo cuya sombra detienen sus pasos un apuesto mancebo de tostado rostro, de negros e inteligentes ojos y de esbeltas formas, y una arrogante mujer, cuyo severo perfil romano y mirada profunda y avasalladora, imponen la admiración y el respeto. El vestido negro que la cubre, realza la majestad de su tez, dorada por nuestro esplendoroso sol tropical.

La hermosa mujer decía al mancebo.

-Ya ves que la comisión de que te encargo, valía la pena de que hubiese venido personalmente en busca tuya.

- Te lo repito, Juana, yo habría acudido al Villar en el acto de recibir tu aviso.

- ¿Podría contar con tu exactitud conociendo la sensibilidad de tu corazón y los encantos de la preciosa hija de Ronsardes?

La frente del joven se tiñó de un vivo encarnado; pero su interlocutora, suavizando el sonoro timbre de su voz, prosiguió sin darle tiempo para replicar (Anzoátegui de Campero 2006: 164).

Basta con leer la presentación inicial de los personajes para detectar la aceptación por parte de la autora de códigos básicos — como la necesidad de fundar una nación, la consecuente urgencia de nacionalizar el idioma, la racialización del sujeto nacional y el deber de legitimar ciertas formas de violencia a partir del amor a la patria- que la ayudarán a sosegar cualquier apreciación contraria a su participación 
en el espacio público. Es decir, en el momento en que Anzoátegui no solo apoya el significante "guerra”, sino que, además, refuerza la estructura maniquea que le sirve de soporte y se solidariza con todo el tejido ideológico que justifica la causa independentista, se está ubicando en el lado del bien para, desde ahí, asignar unos perfiles de identidad tolerables por el campo intelectual a Juan Huallparrimachi y a Juana Azurduy.

Del mismo modo, la autora desarrolla la historia tras la muerte de Manuel Ascencio Padilla, con lo cual, genera la ilusión de estar manteniendo intacta la polaridad hombre/mujer; no obstante, al ver en detalle la cita, se evidencia que la voz narrativa habla de un mancebo de "esbeltas formas", “inteligentes ojos” y "tostado rostro", por contraste con una mujer de "severo perfil", mirada "avasalladora” y digna de "admiración y respeto”; en otras palabras, sí reproduce la dicotomía, pero cambia completamente el signo y las jerarquías entre sus componentes. En la novela se (re)presenta, o trae nuevamente al presente a estos personajes simbólicos asociados a la Guerra de Independencia para reelaborar el sistema sexo-género inscrito en este acontecimiento originario.

Juana Azurduy será entonces la encargada de controlar la violencia y de establecer quiénes y hasta qué punto pueden emplearla. Haciendo uso de su poder, la heroína delegará en Juan Huallparrimachi la posibilidad de enfrentar a Remigio Ronsardes, aunque el carácter apasionado y bondadoso del hombre la haga dudar de su capacidad de actuar con el desapego requerido. Queda en evidencia entonces otro de los rasgos del sujeto nacional traspuesto dentro de la obra, pues el encargado de defender los intereses de la patria será un individuo completamente ajeno al ciudadano liberal y muy cercano al lugar del depositario de la cultura nacional, ${ }^{8}$ mientras que la mujer será vista como la ideóloga amenazante para el enemigo.

\footnotetext{
8 Al momento de pensar el lugar que ocupan las mujeres en los procesos de formación nacional, Nira Yuval Davis y Floya Anthias señalan cinco opciones recurrentes: a) Reproductoras biológicas de los miembros de las colectividades étnicas b) Reproductoras de los vínculos existentes entre los grupos étnicos nacionales c) Participantes cruciales para la reproducción ideológica de la colectividad y transmisoras de la cultura d) Representantes
} 
La forma como los realistas evalúan a cada personaje refuerza esta idea. En el tercer apartado de la obra, titulado "El espía", hay un diálogo entre Remigio Ronsardes, el "mejor amigo, del más cruel y activo cómplice de Aguilera” (171), y Leoncio, un indígena que odia a los independentistas porque los considera responsables del asesinato de su familia. En la casa de Don Remigio conversan:

- Las noticias que me has traído hoy no pueden ser mejores, dijo Ronsardes sin alzar la voz. Así, pues, los nuestros están prevenidos y sólo esperan una ocasión para lanzarse y acabar con los malditos rebeldes. Esa ocasión, Leoncio, es la que necesitamos buscar, y creo que no tardaremos en encontrarla.

—Te escucho, contestó lacónicamente el indio.

-Cuando me avisaste que, a tu paso por Sopachuy, habías visto con Cueto a la endemoniada viuda de Padilla, no pude calcular el motivo que la hubiese sacado de su guarida del Villar; ahora lo sé Leoncio. Ha venido en busca del hijo adoptivo de su esposo para encargarle la ejecución de algún plan importante.

-¿Aquí?

-No, Don Juan se pone en marcha.

—¿Dónde, pues?

—Eso es lo que tú tienes que averiguar, siguiéndolo sin perderle paso. ¿Te conoce?

-No, no lo creo.

-De todos modos, debe ignorar sin duda que militas desde hace poco tiempo en la sagrada causa del Rey; te será fácil ganar su confianza.

y símbolos del discurso ideológico utilizado en la construcción, reproducción y transformación de las categorías étnico-nacionales e) Participantes en las luchas nacionales, económicas, políticas y militares (1989: 7). Cada una de estas tendencias puede entenderse, en mayor o menor medida, como una extensión de la labor maternal, por ello, resulta sumamente interesante que en su afán por ganar visibilidad dentro del espacio público, Lindaura Anzoátegui le asigne a su personaje masculino al menos tres de estos cinco lugares, mientras que le deja a Juana Azurduy el papel de dirigir la guerra, vigilar a sus soldados y censurar la conducta de los hombres bajo su mando. 
Leoncio miró fijamente á Don Remigio.

— ¿Tentar contra la vida de Huallparrimachi?, le dijo. ¡Desgraciado del que lo intente!

- ¿Quién habla de amenazar su vida?, repuso Ronsardes con impaciencia; al contrario, necesitamos que viva Don Juan, porque si muriese ¿cómo podríamos saber los planes de los insurgentes? (171).

Quizás lo primero a destacar de este diálogo es que — tal y como ocurre con buena parte de la novela- se desarrolla en el espacio privado. El hogar va a ser el lugar donde Anzoátegui inscriba las decisiones políticas más trascendentes para la historia de su país. Se trata de un territorio en el que el flujo pasional insta a olvidar la ley y las convicciones religiosas para centrarse en las emociones. Por ello, no es sorprendente que Ronsardes en lugar de solicitarle a Leoncio que asesine a Huallparrimachi, que se enfrente a él o que lo derrote con las armas, le pida que se gane su confianza y, cautelosamente, le saque información. En otras palabras: al ubicar a los hombres al interior del hogar, la escritora consigue diluir las demandas conductuales asociadas a la masculinidad en el siglo XIX latinoamericano. ${ }^{9}$

\footnotetext{
9 Propone Beatriz González Stephan:
}

Ante el inminente desordenamiento que estaba sufriendo el orden social, las marcas de la cultura patricia de estos intelectuales activaron enfáticamente muchos de sus presupuestos, entre ellos, uno, no menos neurálgico, que fue la negociación, en el terreno de las imágenes e ideologías culturales, de la asimilación ente la preeminencia del saber auténtico y noble (es decir, una escritura lejos de los vaivenes del mercado), capaz de agenciar ciudadanías y gobiernos, y la naturaleza heroica y viril de ese liderazgo intelectual; lo que indicaba retener y administrar el patrimonio de las letras en manos de un sector de varones elegidos (el “aristos” del logos masculino).

La construcción de la propia identidad de las elites letradas en la segunda mitad del XIX pasa por las escuelas de derecho, medicina, y las academias de esgrima. En todo caso, el uniforme como vestimenta forma parte de esa fantasía finisecular de monumentalismo heroico que permea la creación artística y también la arena pública. El traje, a manera de disfraz, sirve de escudo para proteger virilidades amenazadas. Las guerras reales pertenecen al pasado. Las guerras de géneros ocupan el presente (2010: 31). 
En principio, tanto Leoncio como Huallparrimachi se presentan como vulnerables: ninguno de los dos emplea la violencia por convicción, ambos lo hacen por mostrar obediencia; la motivación que los lleva a tomar parte activa en la guerra es meramente afectiva - se trata del amor hacia el padre sustituto en uno de los casos y hacia la familia en el otro- y ninguno de los dos hombres se muestra autosuficiente. Ambos encarnan una masculinidad no normativa que solo es visible dentro del hogar y que no va a ser censurada en ningún momento por la voz narrativa. Al contrario, va a ser justificada a partir del relato del pasado de los personajes. Huallparrimachi le debe gratitud al hombre que lo acogió y Leoncio siente odio hacia quienes considera responsables de la destrucción de su casa, los sentimientos de los dos han sido educados por el entorno, de ahí que tanto el apasionamiento como la sumisión sean compresibles.

Ciertamente, se podría pensar que, gracias a una visión colonizada del pasado, la condición de indígenas de los personajes les impide adscribirse completamente al modelo de masculinidad hegemónico; no obstante, a diferencia de lo que solía ocurrir en los relatos independentistas de la gran historia, Huallparrimachi no se subordina -o al menos no en el momento histórico que se construye dentro de esta obra- a un hombre blanco, sino a una mujer viuda, mestiza y cuestionada por la iglesia. Anzoátegui le da a su protagonista un lugar completamente utilitario dentro del enfrentamiento bélico, en este diálogo, representa al "hijo adoptivo de Padilla" como alguien que tiene información valiosa, ejecuta planes y puede ser fácilmente manipulado. Paralelamente, Ronsardes declara a Juana Azurduy su enemiga ideológica y personal: la llama "endemoniada", le reconoce la potestad de diseñar planes y, pretendiendo esgrimir una moral universal, la inscribe entre quienes se enfrentan a la "sagrada causa

Como se ve en la obra de Anzoátegui, la ideóloga de la independencia es mujer, el hombre que está en el campo de guerra es un poeta de origen indígena ajeno por completo al aristos masculino y quienes deciden hacerle frente no usan herramientas heroicas ni exclusivamente viriles, en este sentido, se evidencia como uno de los fines de la recuperación del pasado, el replanteamiento de las identidades de género. 
del rey". Indudablemente, los protagonistas de la novela encarnan identidades alternativas a los modelos tradicionales de género que dominaban en el intersilglo latinoamericano.

Inclusive, la representación de Blanca, la hija de Remigio Ronsardes y amada de Juan Huallparrimachi, ostenta algunos puntos de fuga dignos de atención. En el apartado titulado "Padre e hija", se presenta un diálogo que da cuenta de ello:

— ¡Oh!, —dijo la rubia niña, dejando correr las lágrimas que llenaban sus ojos desde el principio de esta violenta entrevista—, si ella [su madre] hubiese vivido, ¡cuán distinta habría sido nuestra suerte! ¡Noble y bondadosa madre mía! ¡Con qué dulce empeño borraba los resentimientos nacidos al calor de las pasiones de partido! Su benéfica influencia era bastante poderosa para rodear a $\mathrm{Ud}$. del respeto de todos y calmar los arrebatos a que, por desgracia, era arrastrado Ud., padre mío, en esa ardiente lucha política.

Ella habría mantenido a Ud. en las heroicas filas patriotas, y no hubiera llegado la ocasión de oír acusar a Ud., como yo le he oído, padre mío, de amigo de Aguilera y...jcómplice de sus crueldades! [...]

De pie ante la aterrada niña, lívido y convulso, murmuró sordamente.

— ¡Ella acusando á su padre!...¡dando la razón á mis enemigos!... defendiendo a mis verdugos... simpatizando con ellos!...

Y extendiendo un brazo sobre la cabeza de Blanca.

-Hija desnaturalizada, exclamó con voz sibilante, yo te mal...

— ¡Perdón!, gritó Blanca, cayendo de rodillas y abrazándose de Ronsardes, loca de terror [...]

Hija sumisa, no desobedeceré á mi padre... no seré de Juan, pero jamás me llamaré esposa de otro hombre (Anzoátegui de Campero 2006: 175-176).

Pese a que se trata de una escena de sometimiento, es evidente que, en este diálogo, Anzoátegui ha deslastrado al signo mujer de buena parte de las significaciones que se le atribuían. Por ejemplo, resulta muy elocuente no solo que - al contrario de lo que ocurría con su marido - la madre de Blanca haya sido adepta a la causa 
patriota, sino que además, se reconozca en ella el poder de controlar las convicciones ideológicas de don Remigio. Es cierto, el hecho de que esta capacidad de fiscalizar el pensamiento del varón realista se base en el amor suaviza a la figura materna y la inscribe en cierta tradición literaria de mujeres que con la belleza seducen a los héroes y desvían los destinos de una nación; no obstante, en este caso, se trata de una mujer que asume la postura ideológica avalada tanto por la novelista como por la historiografía oficial. Es decir, pese a que se sostenga el sustrato binario mujer amorosa/hombre racional, en este caso, se establece que ella comprende con mayor propiedad el espacio público y toma mejores decisiones en torno a la vida política nacional.

Esto permite que Blanca, pese a su debilidad, pueda inscribirse en un sistema genealógico femenino que dé cuenta de su tránsito por la Historia. Desde el momento en que la madre es presentada como una subjetividad política que, además, tiene la facultad de ideologizar a quienes la rodean, se revalúa la experiencia de ese grupo de mujeres que - a diferencia de Juana Azurduy - vivían el proceso de Independencia desde el interior del hogar. Como se manifiesta en este intercambio, ni siquiera Blanca - que es el personaje más cercano a los estereotipos femeninos manejados en el romanticismo- defiende una causa política por influencia masculina, sino que elige a Juan Huallparrimachi como objeto del amor por la afinidad ideológica que existe entre ambos.

A partir de ello, la resistencia al matrimonio que declara Blanca toma otro cariz. No se trata de desobedecer la ley del padre solo por cumplir una promesa de amor romántico, sino por amor a la patria. El carácter histórico de la novela la convierte en un discurso épico en el que ser independentista o promonarquía puede transformar a una persona en virtuosa o en odiable. Adicionalmente, Blanca, en su condición de mujer, será la encargada de transmitir la cultura y llevar a cabo la reproducción ideológica de la colectividad (Anthias y Yuval Davis 1989), de ahí que la negativa a casarse con un hombre distinto a Huallparrimachi no sea una decisión que solamente atañe al espacio privado. 
Por contraste con este desinterés de la mujer hacia el aspecto físico de su amado, aparece un personaje masculino que permanentemente intenta evaluar la belleza o fealdad de quienes lo rodean. El Mayor La Madrid, un hombre voluntarioso, está decidido a asaltar Chuquisaca. Juana Azurduy tiene la información y la capacidad analítica suficiente para saber que fracasará, así que le solicita al Huallparrimachi que lo detenga. Cuando el representante de los incas se acerca para darle el mensaje al militar, la voz narrativa indica que este percibió a "un apuesto mancebo, de moreno rostro y leal e inteligente mirada” (Anzoátegui de Campero 2006: 181). Luego, al leer el mensaje que le entrega, comenta:

La Madrid tomó el pliego de manos del joven y lo recorrió rápidamente.

- ¡La ilustre Juana de Azurduy en la cabeza!, exclamó con viva satisfacción, las proposiciones son tentadoras, lo confieso; pero, si yo las rechazase, empeñado como estoy en llevar adelante mi imposible empresa (y recalcó irónicamente esta frase). ¿qué consecuencias me atraería mi obstinación?

-Las más deplorables para nuestra santa casa, contestó Juan con firmeza, porque la derrota de las fuerzas que $\mathrm{Ud}$. conduce, desmoralizaría el espíritu de los nuestros, y privándonos de su valioso contingente, daría mayor aliento a los enemigos, inclinando a su favor esa porción indecisa y fluctuante de nuestras poblaciones.

-Tú te pones siempre en el peor de los casos, muchacho, dijo el joven Mayor impaciente.

—El más probable y sobre el que debemos basar nuestras deducciones.

-Yo no lo juzgo absolutamente de ese modo. La plaza de Chuquisaca tiene una pequeña guarnición en la actualidad.

-Pero aguerrida y tras excelentes barricadas.

- iTanto se me da de ese puñado de hombres y de esas paredes de tierra!

-La población está armada y acudirá á la primera señal de Vivero, — ¡Bah! ¡Paisanos con fusiles! ...¡Qué farsa! (183). 
Después de que La Madrid fracasa en su empresa "aferrado a su proyecto, volvió por segunda vez a poner sitio a la ciudad, lleno de confianza, pues contaba con un numeroso auxilio de indios y con los refuerzos que le trajeran Fernández y Ravelo" (Anzoátegui de Campero 2006:183). Estos acontecimientos demuestran que, pese a su formación militar o quizás como consecuencia de la misma, este personaje no está facultado para leer, valorar e integrar las voces alternativas que ya eran parte de la construcción nacional y que tenían más herramientas que el ejército formalmente constituido para salir triunfantes en la consolidación de la patria. Para La Madrid, Azurduy es admirable, pero no digna de ser escuchada; Huallparrimachi es apuesto, pero no portador de razón; la guarnición está armada, pero no lo suficientemente fuerte como ser temible; es decir, el Mayor reproduce buena parte de los juicios reflejados por la elite letrada decimonónica acerca de la construcción nacional y, por eso mismo, cae derrotado.

A contrapelo del discurso letrado latinoamericano, Lindaura Anzoátegui le da mayor poder al colectivo -que, en este caso, además, está dirigido por una mujer estratega- que a la racionalidad letrada. Con ello, borra toda posibilidad de leer a la masa que está en proceso de convertirse en pueblo, como un cuerpo amenazante. ${ }^{10}$ Con esta ficción histórica, la autora racializa al sujeto nacional y, a pesar de que delinea voces y rostros femeninos dentro de la multitud, le resta a la muchedumbre el carácter caprichoso y vengativo que la sobreemocionalizaba y la hacía poco confiable; paralelamente, la tozudez y el afán de gloria se van a convertir en una característica del militar cuyo deseo de figuración opacará los ideales independentistas.

\footnotetext{
10 Es importante recordar a Graciela Montaldo (2010) cuando asegura que "la masa, la multitud, es un sujeto que ha sido, desde su aparición, feminizado. Es precisamente por ser el lado oscuro de lo social, la cara conflictiva de la vida en común, por lo que se usan las características femeninas para describirla. Es voluble, instintiva, caprichosa, vengativa, excesiva" (128). Al leer la obra de Lindaura Anzoátegui, es visible cómo al cambiar el signo de la feminidad también se modifica la representación de la multitud.
} 
Finalmente, es importante destacar la referencia que hace Huallparrimachi, presumiblemente guiado por Anzoátegui, acerca de una "porción indecisa y fluctuante" (183) de la población. Pese a que de forma recurrente la autora ha empleado la dicotomía realista/ patriota para contaminar las categorías de heroísmo y villanía con nuevas subjetividades, en este diálogo deja ver que la cercanía o lejanía a los ideales de la Independencia constituía un conflicto ideológico solo para las minorías. Según Anzoátegui, para 1816, existía un grupo importante de bolivianos que permanecía al margen de esta pugna; no obstante, deja claro que a los dudosos también se les debía considerar dentro de la construcción nacional.

Asimismo, resulta significativo que, dentro de esta novela, el colectivo de personas vacilantes, sin convicciones políticas claras no tenga un marcaje racial específico ni esté constituido predominantemente por mujeres. De hecho, los dos personajes más visibles de este grupo son Leoncio, el indígena manipulado por Ronsardes, y Pérez Cueto, "estudiante distinguido que fue en el Real Colegio Seminario de San Cristóbal, en la ilustre ciudad de Charcas” (Anzoátegui de Campero 2006: 194). Estos hombres, con orígenes étnicos y socieconómicos distintos, engrosan la lista de los confundidos, mientras que Juana Azurduy, Blanca Ronsardes y Carmen, la hija de Leoncio, si bien representan tres modelos de feminidad radicalmente distintos entre sí, tienen posiciones políticas comunes, convicciones ideológicas firmes y cuestionan a quienes no las comparten con ellas.

Además de desestabilizar esta visión esencialista de la mujer, Anzoátegui se dedica a transfigurar otros estereotipos. Por ejemplo, cuando Juan Huallparrimachi le indica a La Madrid que Azurduy es su hermana, el Mayor le responde sorprendido:

— ¿Tu hermana dices?

- Verdad es: debía darle el título de madre, porque lo ha sido y sigue siendo para mí, pero el de hermana responde mejor a su edad y a la confianza que le tengo.

- ¿A su edad? 
-Me lleva con pocos años.

—¿Qué oigo?... ¡Y yo que me la figuraba ya bastante cansada! ¡Hombre!, y debe ser una real moza, ¿verdad?

El entusiasmo del joven Mayor hizo sonreír a Juan, pero recobrando su seriedad le contestó gravemente.

-Doña Juana Azurduy de Padilla es una mujer que sólo puede inspirar admiración y respeto.

-Y para producir esos sentimientos, tiene por fuerza que ser hermosa. Ya me tarde ponerme á las órdenes de mi bella Coronela. (191)

Tras este comentario, la autora introduce una nota aclaratoria en la que indica: "El Gobierno de Buenos Aires, en honrosísima nota de 13 de agosto de 1816, le confirió [a Juana Azurduy] el grado de Teniente Coronel años más tarde, el Libertador le dio los despachos del Coronel" (191), es decir, recalca que el rango militar de Azurduy es un dato cierto, mientras que la belleza física o la relación que se pretendió establecer en las mujeres entre su fealdad y su interés en la política son poco más que percepciones equivocadas de un militar presuntuoso. Por otra parte, la sentencia también propone que la guerra es un escenario abierto para identidades no masculinas y no occidentalizadas, de ahí que personas genérica, cultural, social y económicamente distintas logren ser parte de la misma y, lo que es aún más importante, consigan hermanarse en medio del proceso de lucha.

La construcción horizontal de lazos sociales hará de ese cuerpo indiferenciado que se entendía como "masa” un conjunto de sujetos políticos que no se regirán según los parámetros instituidos por las elites decimonónicas latinoamericanas para definir la masculinidad. Paradójicamente, el tan temido afeminamiento producto de la sensibilidad romántica solo es adjudicado a un Mayor voluntarioso y frívolo que, pese a ello, mantiene una ética competitiva y busca figurar como individuo. Al mismo tiempo, la relación entre Juana Azurduy, Huallparrimachi, la hija de Leoncio, Blanca y otra serie 
de identidades distintas a la del sujeto masculino republicano se van a cohesionar con un vínculo fraterno, lo que acaba por desnaturalizar la presencia de la mujer-madre en los proyectos políticos. No se trata solo de extender al espacio público las labores propias del espacio privado, sino también de generar formas de comunicación distintas entre personas con rasgos de identidad disímiles.

Esta pluralidad, por otra parte, contribuye a refutar que la participación de las mujeres y de los indígenas en la Guerra de Independencia fuera algo extraordinario. En esta novela no solo se relata cómo Juana Azurduy, mujer excepcional, logró actuar a favor de la causa independentista, sino que también se nombran varios colectivos en los que las marcas diferenciadoras de la identidad no limitan las preferencias ideológicas. Leyendo al sesgo el discurso historiográfico, la obra de Anzoátegui no destaca ni en Blanca ni en Carmen ni en Juana la tendencia a la violencia, el carácter temerario o algún otro rasgo comprendido como masculino dentro de la lógica letrada del siglo XIX, sino que en esta obra se construyen mujeres que expresan el miedo, el amor y el odio tal como lo establecía la ética del romanticismo latinoamericano y desde ahí, desde esa sensibilidad, consiguen tomar parte en el espacio público.

La novela cierra, de hecho, con la trágica muerte de los amantes: cuando Ronsardes descubre a Blanca y a Huallparrimachi juntos en su propia casa, se abalanza sobre ellos para asesinarlos. Simultáneamente, llega Leoncio, quien ya sabía que los patriotas no eran los responsables de la muerte de su esposa y, por ello, había decidido vengarse de don Remigio. Tras la muerte de los protagonistas, el indígena, entonces, mata al realista, cuya sangre se mezcla en el suelo "con la ardiente y generosa de los dos amantes" (Anzoátegui de Campero 2006: 218). Podría creerse que se trata de un relato desesperanzador, en el que no es posible el nacimiento de una nueva patria; no obstante, se añade un apartado final en el que se habla acerca de los sobrevivientes:

A la indecisa claridad del crepúsculo de aquel infausto día, se hallan arrodilladas al pie de una tosca cruz, clavada sobre un montón de tierra, frescamente removida, Juana y Carmen, orando con profundo 
recogimiento. A pocos pasos y en actitud respetuosa, Don Jacinto y Cueto Pérez, de pie, guardaban silencio; mientras Leoncio y el leal y anciano Diego, dejaban correr libremente sus lágrimas.

Juana alzó al fin su noble y hermosa cabeza, dirigiendo una larga y melancólica mirada al poético sitio que encerraba una tumba. Las desnudas ramas del tarco, protector de la cabaña, se agitaban sobre ella, batidas por el gemidor y helado viento de junio.

- ¡Así terminan las pasiones y los odios humanos!, pensó Juana con indecible desaliento. ¡Víctimas y verdugo, duermen ahora juntos y en paz, el sueño eterno!...

Juan, hijo mío, yo no te digo adiós... Tú no has hecho más que anticiparte en el camino que seguiré en breve para unirme con mi esposo!

$\mathrm{Y}$ pocos momentos después, la soledad y las tinieblas rodearon la humilde tumba, que guardaba ella sola el secreto de aquel sangriento drama (221-222).

Luego del cierre, se oye de nuevo la voz de Anzoátegui en una nota al pie: "Dios no escuchó el deseo de la noble mujer: la destinaba para probar hasta donde llega el olvido y la ingratitud de un pueblo. Juana Azurduy de Padilla, la heroína de cien combates, la patriota abnegada, vegetó en la oscuridad y murió iiindigente!! En 1861” (222). Aun cuando en este inciso se vuelve sobre el perfil heroico que acompañó al personaje femenino a lo largo de la obra, no deja de ser desconcertante que, en los últimos párrafos de la novela, Azurduy se transforme en una viuda sufriente. La misma descripción física que habla de su "hermosa cabeza” y su "melancólica mirada" indica que la sobreviviente de Manuel Ascencio Padilla y Juan Huallparrimachi va a ser una figura maternal que se define desde su relación con la familia. También puede resultar desconcertante este acercamiento abrupto a la religión católica, sobre todo si se tiene en cuenta que se trata de una ficción histórica, en la que se habla de una mujer que ya no puede ser censurada.

A pesar de ello, si se tiene en cuenta que - como se ha visto a lo largo del texto- Anzoátegui recupera el pasado para teorizar en torno al lugar de la mujer en la historia y, paralelamente, instituir nuevas genealogías, este halo de conservadurismo que rodea a la 
heroína en el apartado final bien pudiera ser un esfuerzo por proteger la propia presencia en la vida política y cultural de Bolivia en la posguerra del Pacífico. Es decir, si pese a sus acciones de guerra y a su tránsito por el espacio público, al final de su vida, Juana Azurduy se transforma en una viuda que también llora el fallecimiento de su hijo de sangre indígena, las mujeres que sigan sus pasos no tienen por qué ser confinadas al espacio privado. Sería pues una de los tantos disfraces que ocultan el proceso reflexivo y de teorización en torno al papel de la mujer, bajo una supuesta apostolización de tradiciones intelectuales más fuertes y mejor avaladas.

\section{Referencias bibliográficas}

Acosta de SAmper, Soledad

2016 José Antonio Galán: insurrección de los comuneros. Bogotá: Editorial Tiempo de Leer.

Anthias, Floya y Nira Yuval-Davis

1989 Woman, nation, state. Londres: Palgrave Macmillan. https:// doi.org/10.1007/978-1-349-19865-8

Anzó́tegui de Campero, Lindaura

1976 Don Manuel Ascencio Padilla. Episodio bistórico. La Paz: editorial juventud.

2006 "Huallparrimachi". En Desafío de mujer: vivir sin el velo de la ilusión: obras de Lindaura Anzoátegui Campero de Campero. Lindaura Anzoátegui de Campero. La Paz: Plural, 161-222.

Ayllón, Virginia

2012 "Fin de siglo XIX en Bolivia: aproximación comparativa de las narrativas de Lindaura Anzoátegui de Campero y Adela Zamudio”. En Escritoras del Siglo XIX en América Latina. Ed., Sara Beatriz Guardia. Lima: Centro de Estudios La Mujer en la Historia de América Latina, CEMHAL, 399-403.

Ayllón, Virginia y Cecilia Olivares

2002 "Las suicidas: Lindaura Anzoátegui, Adela Zamudio, María Virginia Estensoro e Hilda Mundy". En Hacia una crítica de la literatura en Bolivia. Coord., Blanca Wierthüchter. La Paz: PIEB, 149-183. 
BARRAGÁn DE Toscano, Refugio

1887 La bija del bandido o Los subterráneos del Nevado. Guadalajara. México D.F.: El Católico.

Bruce Marticorena, Enrique

2013 "La pampa y la violencia irresistible: estética de la crueldad masculina en Domingo Sarmiento y Esteban Echeverría”. Lexis. Lima, 37, 1, 181-201.

Cabello de Carbonera, Mercedes

1894 Blanca Sol (Novela Social). Lima: Imprenta de Carlos Prince.

Cisneros, Luis Benjamín

1861 Julia, o Escenas de la vida de Lima. París: Rosa E Bouret.

Diez de Medina, Fernando

1954 Literatura Boliviana. Madrid: Aguilar.

Dos ReIs, Maria Firmina

$2004 \quad$ Úrsula: romance. A escrava: conto. Florianópolis: Mulheres.

Freyre de Jaimes, Carolina

1873 Ccora Campillana. (6 entregas). Lima: Revista de Lima.

FINOT, Enrique

1955 Historia de la literatura boliviana. La Paz: Editorial Gisbert.

Glave, Luis Miguel

1996 “Letras de mujer”. Fractal. México D.F, 1, 3, 93-125.

GonZÁlez STEPHAN, Beatriz

2010 "Héroes nacionales, Estado viril y sensibilidades homoeróticas”. En Entre hombres: masculinidades del siglo XIX en América Latina. Eds., Ana Peluffo e Ignacio Sánchez Prado. Madrid: Iberaomericana-Vervuert, 23-58.

Gorriti, Juana Manuela

1929 El tesoro de los incas. Santa fe: Imprenta de la Universidad

Guerra, Rosa

1860 Lucía Miranda. Novela bistórica. Buenos Aires: Imprenta Americana.

Mansilla, Eduarda

2007 Lucía Miranda. Madrid-Frankfurt: Iberoamericana-Vervuert. 
MÁrmol, José

1987 Amalia. México DF: Porrúa.

MÉNDEZ, Cecilia

1995 Incas sí, indios no: apuntes para el estudio del nacionalismo criollo en el Perú. Documento de trabajo $N^{\circ}$ 56. Lima: Instituto de Estudios Peruanos.

Miseres, Vanesa

2014 "Mujeres y guerra en la escritura de Juana Manuela Gorriti (1818-1892)". En Las mujeres en los procesos de independencia de América latina. Ed., Sara Beatriz Guardia. Lima: UNESCO, USMP, CEMHAL, 399-408.

Molloy, Sylvia

1988 "Sarmiento, lector de sí mismo en Recuerdos de provincia". Revista Iberoamericana. Pittsburgh. 54, 143, 407-418. https:// doi.org/10.5195/reviberoamer.1988.4465

MonTALdo, Graciela

2010 "Hombres de la multitud y hombres de genio en eifin-desiécle”. En Entre hombres: masculinidades del siglo XIX en América Latina. Eds., Ana Peluffo e Ignacio Sánchez Prado. Madrid: Iberaomericana-Vervuert, 123-144.

Práxedes Muñoz, Margarita

1897 La evolución de Paulina. Buenos Aires: La Elzeviriana.

Richard, Nelly

1996 "Feminismo, experiencia y representación". Revista Iberoamericana. Pittsburgh. 62, 176-177, 733-44. https://doi.org/ 10.5195/reviberoamer.1996.6256

ScotT, James C.

1990 Los dominados y el arte de la resistencia. Discursos ocultos. México DF: Era.

UnZUETA, Fernando

1997 "Género y sujetos nacionales: en torno a las novelas históricas de Lindaura Anzoátegui". Revista Iberoamericana. Pittsburgh. 63, 178-179, 219-229. https://doi.org/10.5195/ reviberoamer.1997.6239 
2006 “Las republiquetas y los límites de la historiografía”. En Conflictos políticos y movimientos sociales en Bolivia. Ed., Nicholas A. Robins. La Paz: Plural, 121-135.

Vaz Ferreira, Carlos

1945 Sobre el feminismo. Buenos Aires: Losada.

Zorrilla de San Martín, Juan

1955 Tabaré. Montevideo: Biblioteca Artigas, Colección de Clásicos Uruguayos.

Recepción: 26/04/2017 Aceptación: 31/01/2018 